\title{
El 'slang" americano y la jerga mexicana
}

Todo el que, como yo, visita por primera vez a los Estados Unidos procedente de la vecina República Mexicana, se encuentra con la sorpresa de no poder comprender ese pintoresco lenguaje que los americanos hablan y que tan distinto nos parece del que, con tanta dificultad, estudiamos en las escuelas de nuestra tierra bajo el nombre de "Inglés".

Me refiero al "slang”, esa pintoresca fraseología tan comúnmente usada en todos los Estados de la Unión Americana, que casi constituye por sí sola un idioma aparte.

A medida que nos vamos familiarizando con ese lenguaje, nos preguntamos: ¿Tropezará con la misma dificultad el americano que ha aprendido su español en los Estados Unidos al visitar a México y tratar de interpretar nuestras expresiones populares?

Al abordar mi primer "taxi" en este país, no pude disimular mi ignorancia cuando el chofer me informó que "four bits" era el precio del viaje. De nada me sirvió mi inseparable diccionario de bolsillo. Ahora quisiera saber ¿cuál será la reacción de un americano en México ante la expresión tan común entre nuestros choferes de "tostón la dejada"?

Alguien ha dicho que un idioma sin "slang" es un idioma muerto. Si es así, el inglés hablado en los Estados Unidos y 
el español que usamos en México son dos idiomas de una vitalidad sorprendente.

Porque el "slang" de México es tan rico y tan interesante como el de los Estados Unidos. Podría afirmar, sin temor de equivocarme, que cada expresión del "slang" americano tiene su equivalente en el nuestro, y es mi propósito, en este articulejo, hacer un pequeño estudio comparativo de ambos.

La palabra "slang" se puede traducir al español con los nombres de jerga, jerigonza, caló, argot, germanía o galimatías. Usaremos el primero de ellos por ser de significado más amplio y de uso más común tanto en España como en Sudamérica.

La jerga española tiene el mismo origen plebeyo que el "slang" americano. Si estudiamos la que se habla en México, notaremos en seguida tres variedades:

La primera, proviene de las clases más bajas, incultas y peligrosas: criminales, ladrones, rufianes y en general todos aquellos "pájaros de cuenta" que se dedican a actividades ilegales o deshonestas y que se han visto obligados a inventar cierta terminología sólo de ellos conocida, valiéndose de raras expresiones como medio de disfrazar sus malos propósitos. Esta jerga está generalmente compuesta de expresiones burdas, groseras y hasta obscenas y es poco conocida fuera de su propio medio ambiente.

La segunda, que se escucha entre la clase proletaria de México, es la que se asemeja más al "slang" americano por su viveza y colorido. Como en el caso del "slang", esta jerga cambia y varía con las diferentes ramas de trabajo a que la gente se dedica. De este modo, los soldados, los papeleros, los choferes, los ferrocarrileros, los músicos, (I) los actores, etc., tienen cada uno su jerga especial. En esta categoría existe también una jerga general que es familiar a todos los gremios de la clase trabajadora.

Esta jerga está formada por un conjunto de expresiones atrevidas, llenas de ingenio y colorido. En ellas se refleja el 
espíritu humorístico, mordaz y despreocupado de nuestro pueblo. Demuestra, como el "slang" de los americanos, la tendencia de las generaciones jóvenes a librarse de la rigidez del idioma oficial.

Las palabras en ella usadas son correctas y legítimas del idioma español, sólo que empleadas no en su significado literal sino usando sus diversas connotaciones, dejando el resto a cargo de la imaginación, la cual se encargará de descubrir el verdadero sentido de la idea expresada.

Un americano que ha ganado un juego por un pequeñísimo margen, dirá, para expresar cuán cerca estuvo del fracaso: "I won by the skin of my teeth". Expresión disparatada, es cierto; exagerada o falsa, si se quiere, pero que nos trae a la mente una viva idea de proximidad.

Un mexicano, en el mismo caso, diría: "He ganado por un pelo de tortuga". El mismo recurso ha sido empleado, porque las tortugas tienen tanto pelo como los dientes piel.

Con la misma ironía que los americanos llaman "bubble queen" a la lavandera y "thimble knight" al sastre, nosotros apodamos al diccionario "tumba-burros" y al doctor "mata-sanos".

¿Cómo se podría expresar más vivamente la idea de movimiento rápido que con la frase "In two shakes of a dead lamb's tail", o como diríamos nosotros: "En menos que se persigna un cura loco"?

La jerga es disparatada e irreverente, no cabe duda, pero de una precisión admirable. Va directamente "al grano", o como dirían los americanos: "It hits the nail on the head". Carl Sandburg la ha definido ingeniosamente como "un lenguaje que se quita el saco, se escupe las manos y se pone a trabajar".

Tanto en inglés como en español, la jerga sigue el mismo proceso, es decir, nace, alcanza cierta popularidad y desaparece después de una vida más o menos larga, para dejar lugar a 
expresiones nuevas que más tarde seguirán el mismo camino. De este modo, la jerga se renueva constantemente.

Hay sin embargo una diferencia entre el "slang" y la jerga mexicana: ésta nace en cuna humilde, pero humilde muere. Nunca pretende ascender de categoría o filtrarse a las capas superiores de la sociedad, donde es todavía considerada de muy mal gusto. En efecto, su uso es una de las características que distinguen nuestros "pelados" de la "gente decente". Sus expresiones nunca obtienen acceso al lenguaje aceptado.

En cambio en los Estados Unidos, quizá por ser un pueblo más demócrata, el "slang", aunque de origen bajo, no es menospreciado por las clases intelectuales y sus expresiones se hacen muchas veces tan indispensables e insustituíbles, que llegan a colarse en el vocabulario de escritores y oradores de renombre y hasta a lograr ser sancionadas por el uso como inglés correcto.

Existe aún otra clase de jerga en México. Es este un tipo muy especial que no creo lo haya en ningún otro idioma; es posible que ni aun en otro país de habla española. Esta jerga es común entre la gente de la clase media y para apreciarla se necesita tener un conocimiento más profundo del idioma español, un vocabulario extenso y una lengua ágil ("sin huesos"). Este lenguaje consiste en expresiones punzantes y de doble sentido llamadas "albures". (Albur, propiamente hablando, es un juego de naipes en el que se muestran solamente dos cartas a los jugadores y éstos deben adivinar cuál de ellas aparecerá primero).

Los "albures" carecen de sentido para el no iniciado, pero quien los entiende, al escuchar uno de ellos dirigido a él, debe contestarlo con otro mejor y más sutil, entablándose así un verdadero duelo de palabras en el que cada participante trata de "ensartar" (make him "bite") a su contrincante. El vencedor será el que diga la última palabra y la víctima del "albur" el que agotó su repertorio de frases o que no tuvo ingenio suficiente para replicar con una nueva. 
Estos combates amistosos de ingenio y de maña para manejar el idioma español son series de "dichos" ("wisc-cracks"), cada una de las cuales es un juego de palabras (pun) y "tiene cola" (there is a "catch" to it) en tal forma que es un arma de dos filos que con facilidad hará, al inexperto en su manejo, la víctima de la broma.

Tal es la popularidad de esta clase de jerga que ha dado origen a un nuevo género teatral: existen en México algunos teatros pequeños o "carpas" (tent-shows) que por un precio mínimo ofrecen al público un programa combinado de música y diálogos. Estos diálogos, en los cuales los actores representan tipos nacionales, son conducidos en esta clase de jerga y en ellos se "chotea" (se hace mofa despiadada o crítica mordaz) algún mal paso que el gobierno ha dado, los defectos de los políticos de actualidad o los errores de las autoridades locales, todo esto ante la hilaridad y regocijo de los espectadores, quienes son verdaderas "hachas" (expertos, "sharks") en el manejo de este complicado lenguaje.

Como nota curiosa añadiré que las autoridades, víctimas eternas de estas bromas, nada pueden hacer legalmente para suprimir tal género de diversión, pues en realidad, el lenguaje usado es aparentemente inocente y nunca se sale de los límites establecidos por la censura.

La proximidad de nuestros países y el frecuente contacto de nuestras clases laborantes a lo largo de la frontera han dado origen a gran contrabando de palabras y expresiones que de un idioma han pasado al otro contribuyendo a enriquecer tanto el "slang" como nuestra jerga. Hay en ambos idiomas expresiones populares tan semejantes que parecen traducciones literales mas de otras y sería difícil averiguar si originalmente fteron acuñadas en este o en aquel lado del Río Grande.

Los deportes, las películas de cine, el jazz y las invenciones modernas han importado a México un sinnúmero de palabras nuevas que han hallado favorable acogida en el vocabulario de 
nuestras masas. Estas palabras extranjeras, mal pronunciadas o "mexicanizadas", son asimiladas y usadas inconscientemente por nuestro pueblo. Todo americano que visite a México podrá oír expresiones como "oquei" (OK), "nocátu" (knock-out), "jonrón" (home-run), "estécson" (sombrero, ' de Stetson), "fostrot" (fox-trot), "marqueta" (market), "mechas" (matches), "ponche" (punch), "no gari moni" (got no money), "torcido" (tuxedo), "no tengo ni chansa de Chino" (haven't got a Chinaman's chance). Así como el mexicano de visita en los Estados Unidos se sorprenderá ante expresiones tales como "Let's vamoose" (vamos), "savvy?” (¿ ¿abe?), "hoosegow” (juzgado), "Mary Jones" (marihuana), "hombre" (any tough character), "mucho loco" (demente) y "mucho pronto" (de prisa).

Los nombres de las estrellas de cine de Hollywood, tan difíciles para nosotros de pronunciar, contribuyen también al enriquecimiento de nuestra jerga. Es muy común oír el nombre de un actor de cine, pronunciado a nuestra manera, y aplicado como adjetivo a la persona que cree tener ciertas cualidades características de dicho actor. Así cuando un mexicano dice a otro "No seas cargable", en realidad quiere decir: "Tú crees parecerte al actor Clark Gable, pero estás en un error, por lo tanto deja de imitar las maneras o adoptar los aires de él". En la misma forma irónica se oyen los nombres de "Juan Bolas" (John Boles), "Melitón Solís" (Milton Sills), "Juan Barrimuerde" (John Barrymore), "Macarroni" (Mickey Rooney) y otios muchos.

Ante estos disparatados nombres, el visitante americano se divertirá tanto como yo cuando ó a un anunciador de radio en los Estados Unidos presentar a nuestra cantante Luz Morales como la señorita "Loose Morals".

Ya he mencionado antes que cada expresión del "slang" tiene su equivalente exacto en nuestra jerga. Darlos a conocer sería obra superior a mis fuerzas. A título de curiosidad daré 
a continuación una pequeña lista de aquellas palabras y frases que, literalmente iguales, son de uso común en ambos lenǵuajes:

Ace. (As). El que se distingue en cualquier actividad: "Usted es un 'as' en el juego de pelota”.

Anatomy. (Anatomía). El cuerpo humano.

And how! ( $\mathrm{Y}$ en qué forma!). En grado superlativo: "¿Te divertiste en la fiesta?" " $\mathrm{Y}$ en qué forma!"

Bag of bones. (Costal de huesos). Una persona en extremo delgada.

Best half. (Cara mitad). La esposa.

Big ditch. (E1 gran charco). El océano.

Bite the dust. (Morder el polvo). Ser muerto.

Blow by blow. (Golpe por golpe). Descripción detallada en una pelea.

Bottoms up. (Hasta el fondo). Beber hasta la última gota de un vaso de licor.

Bone eater. (Chupa-huesos). Un perro.

Break the ice. (Romper el hielo). Hacerse de confianza.

Bust a gut. (Reventar una tripa). Hacer un supremo esfuerzo.

Chimney. (Chimenea). La persona que fuma demasiado.

Clinch. (Clinche). El acto de abrazarse y cambiar golpes entre los pugilistas. Una escena de amor en el cine.

Count. (La cuenta). La derrota en una pelea.

Chicken heart. (Corazón de pollo). Una persona tímida o cobarde.

Crocodile tears. (Lágrimas de cocodrilo). Sufrimiento que no es sincero.

Dead soldiers. (Soldados muertos). Botellas vacías.

Fathead. (Cabezón, cabezudo). Persona estúpida, terca.

Fed up. (Harto. Hasta el gaznate. Hasta el copete). Cansarse de algo: "Estoy hasta el copete de ir a la escuela",... "Estoy harto de"...

Funnies. (Los monitos). La sección cómica de los periódicos. 
Glass jaw. (Quijada de vidrio). Un pugilista que es fácilmente derrotado.

Groggy. (Grógui). Ofuscado, mareado, borracho.

Get away with its. (Salirse con la suya). Hacer lo que uno quiere, sobre todo en asuntos de naturaleza turbia, dudosa o ilegal. Globetrotter. (Trotamundos). El que viaja constantemente.

Go like hot cakes. (Venderse como pan caliente). Alcanzar rápida popularidad o gran demanda.

Good pay. (Buena paga). La persona que paga puntualmente sus deudas.

Guts. (Tripas). Valor. Audacia. Atrevimiento.

Harness. (Yugo). Empleo regular. Trabajo. "Vamos al yugo". Henry, Henrietta. (Forcito, fotingo). Un automóvil de Ford. Hit the bull's eye. (Dar al blanco). Atinar, adivinar. Tener éxito. Hit the nail on the head. (Dar en el clavo). Tocar el punto más importante. Ir directamente "al grano".

Hoof, To hoof. (Las pezuñas. Andar a pezuñas). Caminar a pie. In mourning. (De luto). Traer las uñas sucias.

In the dark. (A oscuras. En ayunas). Carecer de información acerca de algo. No comprender alguna cosa por falta de información

Iron money. (Fierros). Dinero.

Jackass. (Burro. Asno). Una persona de poca inteligencia.

Keep one's eye peeled. (Pelar los ojos. Con los ojos pelones).Estar alerta. Vigilar cuidadosamente.

Kick. (Patada). Sensación pasajera de alegria.

Kick off. (Estirar la pata). Morir.

Kiss the canvass. (Besar la lona). Ser derribado al suelo de un golpe.

Knee deep. (Hasta la rodilla). En demasía: "Estoy lleno de deudas hasta la rodilla".

Lamps. (Linternas). Los ojos. "Linterna apagada" es un tuerto. Lose by a whisker. (Perder por un pelito). Perder por un pequeño margen. 
Lose a handful of teeth. (Escupir los dientes). Recibir un fuerte golpe en la boca.

Limit. It's the limit. (Es el límite. Es el colmo). Cuando llega al grado de no poder ser soportado más. Incréble. Intolerable. Map. (Mapa. Fachada). La cara.

Nine. (Novena). Equipo de pelota.

Not my funeral. (No tengo vela en ese entierro). No es asunto de mi incumbencia. No me importa.

Pain in the neck. (Dolor de estómago. Dolor de cabeza). Una persona desagradable cuya compañía no es disfrutada. Sensación desagradable.

Pull the zool over one's eyes. (Dar la muleta). "Muleta" es el trapo rojo usado por el matador para distraer la atención del toro antes de matarlo. Engañar. Mentir.

Revenge. (La revancha). Vencer a un oponente en un juego después de haber sido vencido por él.

Screw loose. (Tornillo flojo). Demente. Alocado. Bobo.

Screwy. (Torcido). Tonto. De poca seriedad.

So what! ( $Y$ qué!) ¿Y a mí qué me importa eso? ¿Eso qué tiene que ver con el asunto?

Square. (Cuadrilátero). El lugar donde se efectúan las peleas de pugilato.

Sunday best. (Dominguero). La mejor ropa. Las mejores maneras. "Mi traje dominguero".

Sure Mike! (¡Seguro Miguel!). Enfática afirmación. Sí. Seguramente.

Throw in the towel. (Aventar la toalla). Darse por vencido. Considerarse derrotado o sin ánimo para continuar una empresa.

Title. (El título). El campeonato, en cualquier deporte.

Tools. (Fierros). Los cubiertos de la mesa: cucharas, cuchillos, tenedores.

Tie up a dog with a sausage. (Amarrar perros con longaniza). Ser indiscreto. Confiar cosas de valor a desconocidos. 
Uppercut. (Opercút). Golpe de abajo arriba en la quijada.

Under the table. (Debajo de la mesa). En estado de ebriedad. "Salir por debajo de la mesa". (Babble nonsense, like a drunk person).

Wet one's goozle. (Remojar el gaznate). Beber licor.

Roberto Guerrero de la Rosa, Universidad Nacional de México.

(1).-Cf. Roberto de la Rosa: "Del lenguaje corriente de los músicos mexicanos", Investigaciones Lingiiisticas, IV, 49-50. 